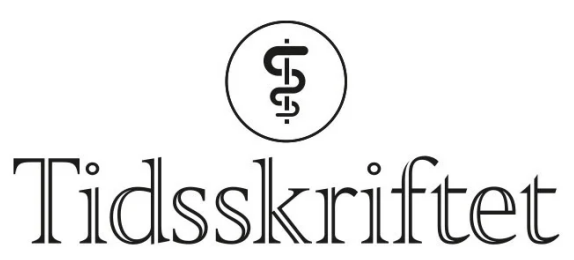

DEN NORSKE LEGEFORENING

\title{
Høytflygende anatomi (med litt klinisk ornitologi)
}

SPRÅKSPALTEN

\section{SVERRE MYREN}

Sverre Myren (f. 1986) er medisinstudent ved Norges teknisk-naturvitenskapelige universitet og spaltist i Gatemagasinet Sorgenfri.

Email: sverre@myren.nu

Norges teknisk-naturvitenskapelige universitet

\section{JOSTEIN HALGUNSET}

Jostein Halgunset (f. 1951) er førsteamanuensis ved Institutt for laboratoriemedisin, barne- og kvinnesykdommer, Norges teknisk-naturvitenskapelige universitet. Han underviser medisinstudenter i anatomi og legelatin.

Norges teknisk-naturvitenskapelige universitet

\section{Kunnskap om ordenes opprinnelse gjør det enklere å forstå} anatomiske navn. Innsikten kan noen ganger gi oss følelsen avå fly.

Mange anatomiske uttrykk kommer av likheten strukturene har med planter og dyr. Den komparative anatomien regnes som grunnlagt av franskmannen Pierre Belon (1). Skal vi tro en illustrasjon fra hans bok fra 1555, L"Histoire de la nature des oyseaux (Fuglenes naturhistorie), er vi alle innerst inne fugler (fig 1$)(\underline{2})$. 

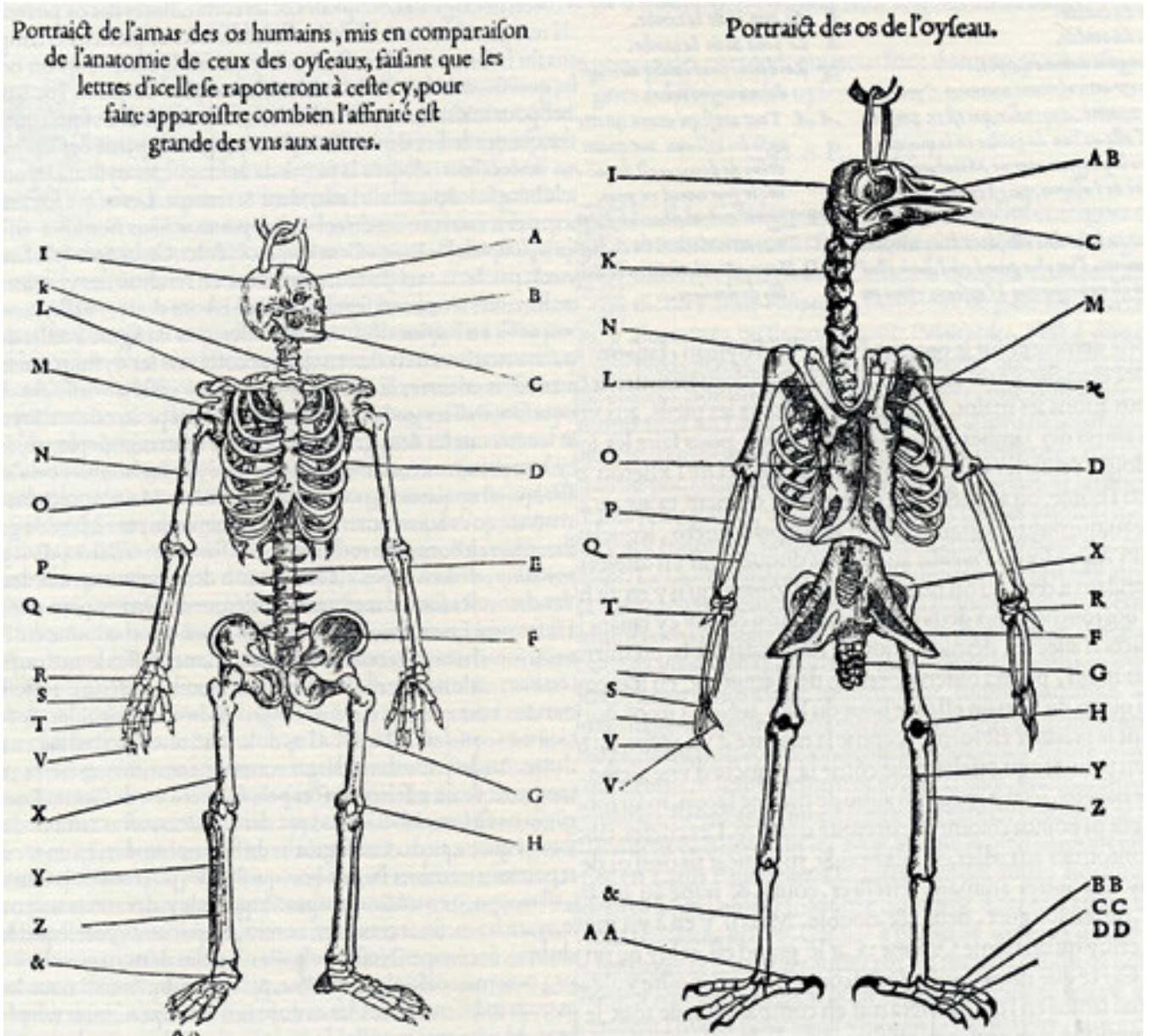

Figur 1 Sammenlikning av skjelettet til fugl og menneske. Fra Pierre Belons L"Histoire de la nature des oyseaux fra 1555

Fra nevroanatomien har vi de latinske retningsbetegnelsene «rostralt» (mot nebbet eller snuten) og «kaudalt» (mot halen eller kroppsenden)(3). Trass i en viss evolusjon har vi mennesker opptil flere nebb rundt om på kroppen. I hjernen finner vi rostrum corporis callosi - den forreste, nedadrettede spissen av corpus callosum. Enkelte anatomiske oppslagsverk (4) angir at «rostralt» betegner retningen mot nettopp dette nebbet. Et annet nebb er processus coracoideus, av gresk korax = ravn, som er ravnenebbutspringet på scapula, der det korte bicepshodet har sitt utspring. En annen viktig albuefleksor, m. brachialis, fester på processus coronoideus proksimalt på ulna, og denne strukturen har sannsynligvis fått sitt navn fordi den likner på et kråkenebb. Det samme gjelder fremspringet av samme navn på mandibula, som tjener til feste for $\mathrm{m}$. temporalis.

\section{Fjær og vinger}

Riktig så staselig er det at vi også har en hanekam, crista galli, av latin gallus = hane. Den rager som en kam opp av os ethmoidale. Dette silformede beinet utgjør den øverste delen av neseskilleveggen, og n. olfactorius forløper her inn i kraniet. Ved et slag mot nesen kan hanekammen forskyves innover og føre til skade på hjernen (5).

Dessuten er det ikke bare fuglene som har fjær. Hos mennesket kan skjelettmuskler klassifiseres som spolformede (fusiforme), uni- eller bipennate. Pennatus er latin for «fjærformet». «Pennat» uttrykker at muskelfibrene hefter på senen som strålene på et fjærskaft (3).

Og vinger har vi mange av! Vi har for eksempel nesevingene, alae nasi, av det latinske ala, som betyr «vinge». Nesevingene kan vi løfte ved hjelp av muskelen med det kronglete navnet $\mathrm{m}$. levator anguli oris alaequae nasi. Og flere bein er forsynt med vinger. Slik er det med nevnte crista galli og plogskjærbeinet vomer, foruten os ilii og sacrum. 
Men vårt mest bevingede bein er uten tvil os sphenoidale, som har to par vinger, nemlig alae majores og alae minores, og dessuten en processus pterygoideus. Denne siste har sitt

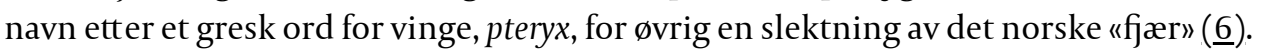
Samme ord ligger også til grunn for betegnelsen pterygion eller pterygium på en reaktiv bindevevsproliferasjon i conjunctiva, som kan vokse som en slags vinge inn over cornea og hemme synet.

\section{Fra nebb til stjert}

Om man flyr eller ei - det er greit å ha bein å gå på. Vi er for sikkerhets skyld forsynt med tre par gåseføtter. Den mest berømte, pes anserinus, er seneutbredningen svarende til festet av de tre lårmusklene mm. sartorius, gracilis og semitendinosus medialt på øvre del av tibia. De to andre gåseføttene er av alle steder plassert i ansiktet, og de betegner her nerveforgreninger. Den store foten, pes anserinus major, er forgreningen av $\mathrm{n}$. facialis i parotiskjertelen. Der n. trigeminus' andre gren løper gjennom foramen infraorbitale under øyet, deler den seg i pes anserinus minor (3). Nerven som forgrener seg her, $\mathrm{n}$. infraorbitalis, er sårbar ved ansiktsfrakturer (7.).

I den andre enden av kroppen er halebeinet. Det latiniserte navnet coccyx kommer av greske $k o k k y x=$ gjøk. Setter man sammen to eksemplarer av de krokete halebeina, kan de sammen minne om et gjøkenebb (3). Vi mennesker er altså fugler fra topp til tå, og også fra nebb til stjert.

\section{LITTERATUR}

1. Belon P. www.britannica.com/EBchecked/topic/6oo49/Pierre-Belon (26.3.2012).

2. Belon P. L"Histoire de la nature des oyseaux (1555). www.wikipedia.com (26.4.2012).

3. Nørgaard JR, Holmboe K. Anatomiens navne. København: Nyt Nordisk Forlag Arnold Busck, 2005.

4. Feneis H. Anatomisk billedordbog. København: Munksgaard, 1995.

5. Silben. http://snl.no/.sml_artikkel/silben (17.2.2012).

6. Falk H, Torp A. Etymologisk ordbog over det norske og det danske sprog. Oslo: Bjørn Ringstrøms antikvariat, 1991.

7. Jepsen O, Thomsen KA, Bretlau P et al. Øre-næse-halssygdomme \& hoved- og halskirurgi. København: Munksgaard, 2007.

Publisert: 29. mai 2012. Tidsskr Nor Legeforen. DOI: 10.4045/tidsskr.12.0358

Mottatt 16.3. 2012, første revisjon innsendt 26.3. 2012, godkjent 28.3. 2012. Medisinsk redaktør Raida $\emptyset$ degaard.

(C) Tidsskrift for Den norske legeforening 2023. Lastet ned fra tidsskriftet.no 26. april 2023. 